\title{
Revista \\ Triângulo \\ O COTIDIANO ESCOLAR E A CULTURA DIGITAL: AS POLÍTICAS \\ EDUCACIONAIS DE INCLUSÃO DIGITAL E SUAS RELAÇÕES \\ COM OS SUJEITOS DA ESCOLA E A FORMAÇÃO DE PROFESSORES
}

\section{SCHOOL EVERYDAY AND CULTURE DIGITAL: THE EDUCATIONAL POLICIES OF DIGITAL INCLUSION AND ITS RELATIONS SUBJECTS WITH SCHOOL AND TEACHER TRAINING}

\author{
Aurélio Alberto Richiteli ${ }^{1}$
}

\begin{abstract}
RESUMO
A temática das políticas públicas voltadas para a inclusão digital e a formação de professores para o uso das tecnologias digitais, são temas que suscitam reflexões com relação à maneira como os docentes tem participado e reagido a esses programas de inclusão. Assim, esta pesquisa tem como objetivo analisar como se dá a relação entre formação do professor e o uso de tecnologias na educação como ferramenta que possibilita a aprendizagem dos alunos. Para alcançar este propósito, utilizaremos uma abordagem metodológica de natureza qualitativa, partindo da abordagem teórica com a análise documental dos programas educacionais de inclusão digital e de entrevistas realizadas com professores da rede pública de ensino. Como arcabouços teóricos fundamentais utilizaremos os estudos de autores como José Moran (2007), Maria Elizabete Bianconcini (2005), Pierre Lévy (1999), Pedro Demo (2008), dentre outros autores. Os resultados parciais apontam que há uma deficiência na forma de elaborar programas de formação de professores pelas políticas públicas de inclusão digital.
\end{abstract}

PALAVRAS-CHAVE: Políticas públicas. Inclusão digital. Formação de professores. Educação.

\begin{abstract}
The theme of public policies focused on digital inclusion and the training of teachers to the use of digital Technologies, are themes of reflections with respect to the way teachers have participated and reacted to these programs of inclusion. Thus, this research aims to examine the relationship between teacher training and the use of technologies in education as a tool that allows students' learning. To achieve this purpose, we will use a methodological approach of qualitative nature, starting from the theoretical approach with the documentar analysis of the educational programs for digital inclusion and interviews with teachers of public schools. As fundamental theoretical frameworks we use studies of authors such as José Moran (2007), Maria Elizabete Bianconcini (2005), Pierre Lévy (1999), Pedro Demo (2008), among other authors. The partial results indicate that there is a deficiency in the form of elaborate teacher education programs by the public policies of digital inclusion.
\end{abstract}

KEYWORDS: Public policies. Digital inclusion. Teacher Educacion Program. Education.

\section{INTRODUÇÃO}

A motivação que nos leva a escolha do tema a ser pesquisado é de que as Tecnologias de Informação e Comunicação (TIC) ao longo dos últimos anos vêm recebendo grandes

\footnotetext{
${ }^{1}$ Programa de Pós-Graduação em Educação da Universidade Federal do Triângulo Mineiro - UFTM. E-mail: aurelio.richiteli@hotmail.com.
} 
investimentos dos órgãos públicos. Vários recursos surgiram e adentraram nas escolas públicas, professores e alunos possam estar interagindo com as mídias e com as tecnologias digitais. Com as políticas públicas de inclusão digital surgiram várias propostas para adaptar o uso da tecnologia à dinâmica da sala de aula, na tentativa de acompanhar os avanços tecnológicos e possibilitar a adequação necessária para o ensino-aprendizagem.

O uso das tecnologias digitais no cotidiano escolar, pode funcionar como um instrumento de mediação para o ensino-aprendizagem, tanto para o professor quanto para o seu aluno, otimizando assim a relação de ambos, promovendo o uso favorável das tecnologias, autonomia e a criticidade. Para essa mediação o professor precisa da formação e se adequar para esta nova realidade, para que possa desempenhar seu papel dentro da sala de aula usando toda essa tecnologia.

Essa mediação segundo Peixoto e Carvalho (2011, p.33):

A mediação é um aspecto primordial da psicologia histórico-cultural, caracterizando o fato de que os seres humanos não agem diretamente sobre o mundo. Pelo contrário, as ações são mediadas por ferramentas sóciosemióticas (tais como a linguagem ou a matemática), bem como por artefatos materiais e tecnologias. A esse aspecto, soma-se o entendimento de que a mediação se efetiva no bojo dos processos históricos, institucionais e discursivos, constituindo-se pela atividade prática e simbólica de um sujeito.

E é nesta problemática que entram as políticas públicas na formação do professor para o uso das tecnologias, não só levando as tecnologias em si para a escola pública, mas levando a mediação e formação para o professor.

O problema que vem se arrastando a alguns anos é como utilizar essas tecnologias nas salas de aulas em escolas públicas ou até mesmo como elas vem sendo utilizadas e como formar o professor para trazer estas tecnologias para as salas de aula. Pensamos que ao introduzir as tecnologias na sala de aula, o professor desafia uma rotina anterior, numa mudança de paradigma que compõe uma nova maneira de ensino-aprendizagem. O novo paradigma surge e cria-se também a necessidade de programas governamentais para a inclusão digital $^{2}$ de professores e alunos das escolas púbicas.Dessa forma, não basta oferecer acesso às TICs na escola, é preciso também instituir a democratização no uso e na formação dos professores.

\footnotetext{
${ }^{2}$ Inclusão Digital é um processo contínuo e conflituoso, marcado pela tensão entre homogeinização e proliferação da diferença, tradição e modernidade, necessidade e liberdade, através do qual as TIC penetram contextos socioculturais sempre heterogêneos) transformando-os ao mesmo tempo em que são transformadas pela maneira como os sujeitos as praticam nestes contextos. (BUZATO, 2007, p. 74).
} 
Atualmente temos alguns programas de inclusão digital direcionados às escolas públicas brasileiras, como por exemplo o Programa Nacional de Tecnologia Educacional (ProInfo) e o Programa Um Computador por Aluno (PROUCA):

Programa Nacional de Tecnologia Educacional (ProInfo) - É um programa educacional com o objetivo de promover o uso pedagógico da informática na rede pública de educação básica. Programa Um Computador por Aluno (PROUCA) - uma iniciativa do Governo Federal - foi implantado com o objetivo de intensificar as tecnologias da informação e da comunicação (TIC) nas escolas, por meio da distribuição de computadores portáteis aos alunos da rede pública de ensino. Proinfo Integrado, programa de formação voltada para o uso didático-pedagógico das Tecnologias da Informação e Comunicação (TICs) no cotidiano escolar, articulado à distribuição dos equipamentos tecnológicos nas escolas e à oferta de conteúdos e recursos multimídia e digitais (BRASIL, 2013).

A problemática da nossa pesquisa está em investigar como estão ocorrendo as mudanças, e se estão ocorrendo, na formação do professor para o uso das tecnologias no ensino-aprendizagem, em três escolas municipais da cidade de Uberaba (MG) que participam ou participaram de programas educacionais de inclusão digital. Qual é a infraestrutura ofertada para que aconteçam os programas de inclusão digital, ProInfo e PROUCA? Quais são as condições que a escola apresenta para lidar com a introdução dessas tecnologias e como tem sido o desenvolvimento das mesmas para a potencialização da formação do professor? Nesta perspectiva Maria Elizabeth Almeida (2005, p. 38), aponta que:

[...] a importância da formação do professor para que ele tenha condições de desenvolver práticas pedagógicas com projetos que favoreçam a recontextualização do conhecimento na escola e na vida do aluno, a produção colaborativa de representações que engajam os alunos como aprendizes, construtores de significados. Para enfatizar essas idéias são comentados alguns exemplos de práticas de sala de aula em que tecnologias foram articuladas a projetos para propiciar aos alunos a aprendizagem significativa, por meio do desenvolvimento de produções com o uso de diferentes mídias.

Nos indagamos se o que tem predominado nas situações de ensino-aprendizagem consiste mais em transmissão ou construção de conhecimento junto ao aluno com uso destas novas tecnologias; ou se o professor vem perdendo seu espaço dentro da sala de aula diante das potências tecnológicas, transformando-se em um facilitador, animador ou monitor. Segundo Barreto (2004, p. 1186), "é monitor, nos seus múltiplos sentidos, pode ser uma imagem-síntese da precarização do trabalho docente". O professor, como todos os outros, 
precisa de atualização constante ao longo de sua jornada. Os programas como PROUCA e ProInfo são importantes e necessários pois, de certa forma, devem suprir as deficiências da formação inicial e permitir que os professores troquem experiências com outros educadores desenvolvendo, assim, a aprendizagem ao longo da vida de forma colaborativa, para que ele não se torne apenas um facilitador, animador ou monitor.

O foco desta análise está, então, na prática do professor de escola pública que tem em suas mãos todo um aparato tecnológico proveniente das políticas públicas de inclusão digital. Investigaremos como tem sido realizada a formação para o uso das TICs na rede pública de ensino. Em face das problematizações já citadas nesta introdução buscaremos avaliar o surgimento ou não de mudanças significativas frente aos problemas recorrentes. Do ponto de vista geral, entendemos que esta pesquisa poderá trazer contribuições para os gestores e professores de escolas públicas que recebem os programas vindos das políticas públicas educacionais de inclusão digital.

\section{Problema}

Os avanços tecnológicos vivenciados na sociedade atual têm se inserido de diferentes formas na instituição escolar e implicam reflexos no trabalho cotidiano dos professores, dos alunos e nas maneiras das pessoas agirem e se relacionarem, da mesma forma que também modificam as relações entre sujeitos e informação.

Reconhecendo que quando as tecnologias adentram nas escolas públicas surgem vários desafios a serem superados, dentre eles, as dificuldades enfrentadas pelos professores para uma formação adequada para o uso das TICs, nosso foco para o problema é que muitas vezes, as implementações destes programas desconsideram a formação do professor, as formas de funcionamento das instituições escolares ou mesmo as práticas de ensinoaprendizagem cotidianas da sala de aula, levando a tecnologia por si só para a escola (laboratórios, computadores, Internet, tablets e lousas digitais), sem uma formação adequada para o professor. Formar os professores para o uso das tecnologias é uma das metas desde que foram implantadas as políticas públicas educacionais de inclusão digital:

1) Estruturar um sistema de formação continuada de professores no uso das novas tecnologias da informação, visando o máximo de qualidade e eficiência; 2) Desenvolver modelos de capacitação que privilegiem a aprendizagem cooperativa e autônima, possibilitando aos professores de 
diferentes regiões geográficas do país oportunidades de intercomunicação e interação com especialistas, o que deverá gerar uma nova cultura de educação a distância; 3) Preparar professores para saberem usar as novas tecnologias da informação de forma autônoma e independente, possibilitando a incorporação das novas tecnologias à experiência profissional de cada um, visando a transformação de sua prática pedagógica. (BRASIL, MEC/SEED 1997, p.12).

Dentre os principais questionamentos desta pesquisa citamos: compreender como tem sido realizada a formação do professor para o uso das tecnologias no ensino-aprendizagem na visão do professor e quais ações estes programas de inclusão digital vem executando após tantas críticas, e se eles se reestruturaram no intuito de melhorar o desenvolvimento e o desempenho dos professores. Este profissional da educação consegue hoje ser práticoreflexivo $^{3}$ em sala de aula com uso das tecnologias, após receber essa formação? Como esse professor vem recebendo essa formação, se é favorável nas suas aulas - ou não? Já que o ProInfo foi criado pela Portaria n $^{\circ}$ 522/MEC, de 9 de abril de 1997 e o PROUCA apresentado ao governo brasileiro em janeiro de 2005 no Fórum Econômico Mundial em Davos - Suíça. Temos aí dez anos de PROUCA e dezoito anos de ProInfo, tempo esse que queremos saber se foi suficiente para adequações para uma inclusão digital na formação do professor por esses programas.

\section{Objetivo Geral}

Nesta investigação queremos compreender como as políticas públicas de inclusão digital, estão contribuindo - ou não, para formação do professor e suas práticas pedagógicas.

\section{Objetivos Específicos}

- Analisar se os professores e professoras que participam dos programas de inclusão digital de três escolas municipais da cidade de Uberaba (MG), transformam suas práticas com uso das tecnologias, de modo a valorizar mais os próprios saberes e as possibilidades de reflexão e aprendizagem.

\footnotetext{
${ }^{3} \mathrm{O}$ conceito de professor como prático-reflexivo reconhece a riqueza da experiência que reside na prática dos bons professores. Na perspectiva de cada professor, significa que o processo de compreensão e melhoria de seu ensino deve começar pela reflexão sobre a sua própria experiência. (Zeichner, 1993, p.17).
} 
- Destacar/compreender/analisar como os professores de três escolas municipais da cidade de Uberaba (MG), recebem a formação pelos programas de inclusão digital nos dias atuais, após 5 anos de implementação destes programas nesta escola;

- Compreender/descrever o que vem sendo ofertado pelos programas de inclusão digital nestas três escolas do município de Uberaba (MG) para formação do professor.

- Contribuir/descrever as práticas na sala de aula pelo professor com uso das tecnologias, através desta pesquisa desenvolvida, buscando relatar o que vem dando certo na formação do professor por essas políticas públicas de Inclusão digital.

\section{Justificativa}

A relevância social do problema investigado, é que o uso pedagógico das TICs requer dos professores alteração nas concepções de ensino-aprendizagem e, além disso, conhecimento para o uso delas na sala de aula. O ideal é que sejam ofertadas oportunidades de formação constantes e não apenas pontuais, de modo que os professores possam aplicar na escola o que vivenciam dentro dos programas ofertados pelas políticas públicas de inclusão digital e que tenham a oportunidade de relatar suas experiências e refletir sobre elas. A grande contribuição que traz a nossa pesquisa é na reflexão sobre a prática do processo de formação do professor para o uso das tecnologias em escolas públicas. Se esta reflexão não existir, corremos o risco de continuar apenas a instrumentalizar os professores sem que estes encontrem significado no que aprendem nas formações ofertadas pelas políticas públicas de inclusão digital e não havendo, portanto, qualquer mudança em sua prática docente.

Outro aspecto de relevância da pesquisa, está em buscar dar subsídios ao planejamento e implantação de programas governamentais de inserção de novas tecnologias em ambiente escolar, pois a tecnologia educacional só funciona se for cuidadosamente planejada e implantada com a participação dos professores das escolas, visando ampliar a contribuição destas ferramentas ao ensino-aprendizagem, bem como para se evitar desperdícios de tempo e de recursos financeiros de investimentos em programas de inclusão das tecnologias no ensino. São rotineiras as notícias sobre altos valores de investimento e de desperdício de verbas em programas ligados à “inclusão digital”, tal como:

Boa parte dos computadores não foi entregue nos prazos. Outros foram entregues sem a infraestrutura necessária para sua adoção em sala de aula. $\underline{\mathrm{O}}$ treinamento dos docentes não deu os resultados esperados. O suporte técnico praticamente inexiste. Os laptops que apresentaram problemas acabaram 
encostados em armários ou nos almoxarifados, porque não há recursos. (O GLOBO, 2013, grifo nosso).

Essa pesquisa também visa explorar as possibilidades de uso destas tecnologias no cotidiano escolar, identificar porque muitos professores não conseguiram fazer o uso destas ferramentas, quais são os fatores que interferem nisto e quais práticas foram bem-sucedidas.

Neste sentido Moran (2003, p. 15) alerta que:

Nosso desafio maior é caminhar para um ensino e uma educação de qualidade, que integre todas as dimensões do ser humano. Para isso precisamos de pessoas que façam essa integração em si mesmas no que concerne aos aspectos sensorial, intelectual, emocional, ético e tecnológico, que transitem de forma fácil entre o pessoal e o social, que expressem nas suas palavras e ações que estão sempre evoluindo, mudando, avançando.

Para alcançar resultados realmente satisfatórios com a implementação e utilização das tecnologias como artefato no processo de ensino e aprendizagem, assim como com qualquer outro recurso, é preciso que estes programas promovam a integração entre professor, aluno e escola, de maneira que haja envolvimento deles na prática pedagógica com auxílio das tecnologias.

Essa “prática pedagógica”, para Almeida (2005, p.43):

É uma forma de conceber educação que envolve o aluno, o professor, as tecnologias disponíveis, a escola e seu entorno e todas as interações que se estabelecem nesse ambiente, denominado ambiente de aprendizagem. Tudo isso implica um processo de investigação, representação, reflexão, descoberta e construção do conhecimento, no qual as mídias a utilizar são selecionadas segundo os objetivos da atividade.

A escola, principalmente a pública, necessita saber onde, quando e por que determinado recurso, como as tecnologias digitais, podem lhe ser útil, além é claro, de que forma vai desenvolver o conhecimento adequado junto ao aluno e se haverá investimentos necessários em sua estrutura, organização e apoio técnico que viabilizem seu uso.

\section{Referenciais Teóricos}

Nas escolas públicas, a inserção das novas tecnologias tem chegado via políticas públicas que elaboram e implantam programas de inclusão digital, prometendo ser bons 
aliados na ajuda da transmissão de conhecimento. Para uma análise documental destes programas, o sítio na internet do Ministério da Educação (Portal MEC) é um excelente meio através do qual podemos conhecer a forma como o governo federal leva a tecnologia e a formação do professor para uso em sala de aula.

Um dos autores que julgamos prioritário nesta pesquisa, José Moran (2000), vai dizer que o papel do professor é fundamental nos projetos de inovações, até porque, a qualidade de um ambiente tecnológico de ensino depende muito mais de como ele é explorado didaticamente do que das suas características técnicas. Moran (2007) aponta que ainda não existe um modelo de pedagogia inovadora com as tecnologias na escola, devido a uma má formação do docente.

Moran (2007, p. 102) observa que:

[...] no planejamento didático, predomina uma organização fechada e rígida, quando o professor trabalha com esquemas, aulas expositivas, apostilas, avaliação tradicional. O professor que 'dá tudo mastigado' para o aluno, de um lado, facilita a compreensão; mas, por outro, transfere para o aluno, como um pacote pronto, o conhecimento de mundo que ele tem.

Demo (2008, p.134) reforça que:

Temos que cuidar do professor, porque todas essas mudanças só entram bem na escola se entrarem pelo professor, ele é a figura fundamental. Não há como substituir o professor. Ele é a tecnologia das tecnologias, e deve se portar como tal.

Já Albuquerque (2014, pg. 30) observa que:

[...] é importante que o professor tenha a postura e atitude de proporcionar o desenvolvimento da aprendizagem, é preciso ousar reconfigurar o processo ensino-aprendizagem. Os alunos muitas vezes estão mais informados do que o professor imagina, pois, eles, em geral tem mais tempo para interagir com as mídias o que está cada vez mais didático.

O uso das tecnologias na sala de aula exige do professor planejamento, escolha do tema e respectiva problemática a ser investigada, além de orientar qual vai ser o emprego de distintas tecnologias incorporadas às aulas, de modo a trazer significativas contribuições à aprendizagem. Almeida (2005) destaca que nesta formação do professor, o educador tem a 
oportunidade de vivenciar distintos papéis, como o de aprendiz, o de observador da atuação de outro educador, o de gestor de atividades desenvolvidas em grupo com seus colegas em formação e o papel de mediador junto com outros aprendizes.

Pedro Demo (2011) ressalta que para evitar o instrucionalismo ${ }^{4}$ a necessidade de formação permanente do professor. O autor alerta a importância para o professor de questões como precisar ser um eterno aprendiz, ter direito a estudar e o aprimoramento que deve ser estimulado permanente, e deve haver espaço para estudar dentro da carga horária letiva.

Demo (2011, p. 11) ainda afirma que:

As tecnologias invadem o campo da educação, abrindo, de um lado, oportunidades virtuais praticamente inesgotáveis, e, de outro, reforçando o cinturão de mercado. O descompasso é cada vez maior entre tecnologia e pedagogia, pois enquanto esta caminha lentamente a outra corre à velocidade da luz.

O papel das tecnologias na sociedade e como ela vem sendo usada na sociedade também é abordado por outro autor de fundamental importância nesta pesquisa, o filósofo da comunicação Pierre Lévy (1999). Este autor sinaliza que a sociedade encontra-se condicionada, mas não determinada pela técnica. Tal afirmação permite a percepção da relação que há entre sociedade e tecnologia, mediante a qual a primeira se constitui historicamente pela segunda, embora não seja por ela determinada. Sobre a nova relação com o saber, Lévy (1999) sinaliza o papel das tecnologias intelectuais, como favorecedoras de novas formas de acesso à informação e de novos estilos de raciocínio e de construção do conhecimento.

Utilizaremos também nesta pesquisa, alguns conceitos como "nativos digitais" e “imigrantes digitais" de Marc Prensky (2001). O autor observa os nativos digitais, sendo estes os jovens que nasceram com a tecnologia e são fluentes na linguagem digital dos computadores, dos vídeos-games, redes sociais e da Internet. Imigrantes digitais são aqueles que falam a linguagem digital com sotaque, e que revelam dificuldades em compreender e expressar-se digitalmente.

Necessitamos de muitas discussões e debates para ampliar o conhecimento sobre as tecnologias e a formação do professor para o uso delas, sobre seu processo histórico e

\footnotetext{
${ }^{4}$ Para Pedro Demo, o "instrucionismo" é o apreço exagerado pela aula expositiva, feita por professores que não possuem produção própria. O que faz um professor não é aula, mas autoria.
} 
principalmente quanto ao uso destas tecnologias na sociedade, em geral e, especialmente no âmbito educacional.

\section{Procedimentos Metodológicos}

A metodologia empregada é uma abordagem de cunho qualitativo e de natureza descritiva, apoiada em pesquisa bibliográfica, documental, entrevista semiestruturada e questionário.

1. Estudo bibliográfico - nesta pesquisa centrar-se-á nas contribuições teóricas de vários autores que realizaram obras bibliográficas sobre as formas de utilização da tecnologia pelo professor e sua formação através de programas e políticas públicas de inclusão digital. $\mathrm{O}$ aporte teórico deste estudo a princípio fundamenta-se em Pedro Demo,Pierre Lévy, Maria Elizabeth Almeida e José Manuel Moran bem como outros autores para contribuição nesta área de investigação.

2. Pesquisa Documental - análise da estrutura, objetivos e pretensões destes programas educacionais de inclusão digital, através de sua documentação no site do MEC.

3. Entrevistas semiestruturadas - serão realizadas a partir de um roteiro planejado procurando identificar, dez professores que devem estar participando ativamente dos cursos de formação oferecidos pelos programas de inclusão digital em três escolas públicas municipal situadas na cidade de Uberaba (MG), uma considerada modelo e outras duas situadas em bairro afastado da área central.A caracterização dos sujeitos da pesquisa, visa em avaliar a compreensão da postura destes professores, por meio de métodos qualitativos, pois o objetivo aqui é saber a qualidade da formação do professor através dos programas de inclusão digital. As entrevistas, após serem gravadas, vão ser transcritas em conjunto com os entrevistados com o objetivo de garantir a fidelidade das informações, favorecendo uma abordagem total do problema investigado em suas múltiplas dimensões.

Neste sentindo, as entrevistas semiestruturadas vão ser realizadas a partir das fundamentações metodológicas de José Meihy (2005). Partindo dos apontamentos de Meihy (2005, p.147), o professor que vamos fazer a entrevista é o sujeito mais importante devendo, por meios desse tipo de coleta de dados, ter "[...] maior liberdade para dissertar, o mais livremente possível, sobre sua experiência pessoal", e no nosso caso, também a experiência profissional dele com os programas de inclusão digital. Meihy (2005, p.148), ressalta que na entrevista, visando às narrativas, “[...] as perguntas devem ser amplas, sempre colocadas em 
grandes blocos, de forma indicativa dos grandes acontecimentos". E que "[...] deve ser dado ao depoente espaço para que sua história seja encadeada segundo sua vontade e suas condições". Por fim, Meihy (2005, p.149), observa que a participação do entrevistador deverá ser a menor possível, sendo “[...] sempre estimuladora e jamais de confronto, seja qual for à opção, subjetiva ou não".

\section{Resultados parciais}

Nosso projeto de pesquisa está no início e temos levantamento de bibliografias e documentação das políticas públicas de inclusão digital realizadas no Brasil. Ainda não iniciamos a pesquisa de campo, que serão entrevistas com os professores da rede pública municipal de três escolas situadas no município de Uberaba (MG).

Com a realização da pesquisa bibliográfica, até o momento temos o levantamento de alguns aspectos, como por exemplo o uso da tecnologia nas salas de aula, como o Google Earth, uso dos laboratórios de Informática para pesquisa e trabalhos. Também há dificuldades de adequação das tecnologias digitais na escola pública, e essas dificuldades se agravam quando falamos do professor, pois "A escola precisa formar pessoas com potenciais muito flexíveis, que mudem, transformem e transitem em diversas situações, experiências e contextos" (CASTELLS, 2003). Temos uma necessidade emergencial de formação do professor, pois os professores estão diante do que pode ser considerado, ao mesmo tempo, um grande desafio e uma grande oportunidade de mudança.

Com o levantamento documental sobre os programas de inclusão digital, até o momento temos verificado como as políticas públicas de inclusão digital elaboram seus programas. O PROUCA integra o ProInfo e eles tem como objetivo promover o uso pedagógico da informática na rede pública de ensino fundamental e médio. O Programa funciona de forma descentralizada, sendo que em cada Unidade de Federação existe uma Coordenação Estadual do ProInfo. As escolas são pré-selecionadas de acordo com o Censo Escolar e o IDEB do Município e os professores da rede municipal de ensino são treinados para uso do sistema Proinfo Integrado. O objetivo segundo o Ministério da Educação e Cultura (MEC), é que professores ao participarem do curso de formação aprendam a utilizar as tecnologias digitais na sala de aula com maior segurança, possibilitando implementar situações que contemplem o ensino-aprendizagem. 
Podemos observar a partir dos documentos e bibliografias consultadas e em seguida pesquisa de campo, ou seja, vamos realizar uma entrevista semiestruturada e observações em sala dela aula, com o objetivo de ver as práticas educacionais de professores de três escolas públicas municipais que recebem formação destes programas educacionais para inclusão digital.

Ao final da investigação pretendemos saber como as políticas públicas educacionais de inclusão digital vem dando suporte e contribuindo na formação do professor. Também é nosso objetivo práticas de sala de aula consideradas de sucesso pelos professores que utilizam as tecnologias digitais no ensino aprendizagem.

\section{CONCLUSÃO}

As tecnologias de maneira geral sempre fizeram parte do cotidiano escolar e foram se incorporando a ele sutilmente. Porém, com a chegada das tecnologias digitais como lousa digital, a Internet, câmeras fotográficas, smartphones, tablets e ultra books, dentre muitas outras, sua rápida e constante evolução, os profissionais da educação encontram um novo desafio, acompanhar essa transformação e utilizá-la da melhor forma possível. O governo federal e seus programas de inclusão digital adentraram a escola para utilizar as tecnologias digitais como mediação pedagógica, o que exige estudo e preparação dos profissionais da educação e, portanto, há a necessidade de formação continuada nessa área. Observamos que com as novas tecnologias e saber aproveitá-las depende não apenas das tecnologias digitais em si, mas sim do que se é capaz de se fazer com elas.

\section{REFERÊNCIAS}

ALMEIDA, Maria Elizabeth Bianconcini. Prática e formação de professores na integração de mídias. In: ALMEIDA, Maria Elizabeth Bianconcini de; MORAN, José Manuel (orgs.). Integração das Tecnologias na Educação. Salto para o futuro. Brasília: MEC, SEED, 2005. p. 38-45.

BARRETO, Raquel Goulart. Tecnologia e Educação: Trabalho e Formação Docente. Educação \& Sociedade, Campinas, v.25, n.89, 2004. p.1181-1197.

BUZATO, Marcelo. Entre a fronteira e a periferia: linguagem e letramento na inclusão digital. Tese (Doutorado em Linguística Aplicada) - Instituto de Estudos da Linguagem, Universidade Estadual de Campinas, Campinas, 2007. Disponível em:

$<$ http://www.bibliotecadigital.unicamp.br/document/?Code $=$ vtls000415042\&fd $=y>$. Acesso em: 10 abr. 2015 
BRASIL, MEC / SEED. Programa Nacional de Informática na Educação - Proinfo. Brasília, 1997.

Secretaria de Educação a Distância. Programa Nacional de Informática na Educação. Brasília: MEC/SEED-ProInfo. http://www.prinfo.gov.br, 2013.

Fundo Nacional de Desenvolvimento da Educação. FNDE. Disponível em: $<$ http://www.fnde.gov.br/>. Acesso em: 4 jul. 2015.

CASTELLS, Manuel. A Galáxia Internet: reflexões sobre Internet, Negócios e Sociedade. 2003.

DEMO, Pedro. Pedro Demo aborda os desafios da linguagem no século XXI. In: Tecnologias na Educação: ensinando e aprendendo com as TIC: guia do cursista / Maria Umbelina Caiafa Salgado, Ana Lúcia Amaral. Brasília; Ministério da Educação. Secretaria de Educação a Distância; 2008. Cap. 4.

Formação permanente e tecnologias educacionais. 2. Ed. Petrópolis, RJ: Vozes, 2011.

GASPARI, Elio. "O fracasso do UCA-Total". O Globo. 08 Abr. 2013. Disponível em: http://oglobo.globo.com. Acesso em 31 julho de 2014.

LÉVY, Pierre. Cibercultura. Trad. Carlos Irineu da Costa. São Paulo: Editora 34, 1999.

MASETTO, Marcos; MORAN, José; BEHRENS, Marilda. Novas tecnologias e mediação pedagógica. Campinas: Papirus, 2003.

MEIHY, José. Manual de História Oral. 5.ed. São Paulo: Loyola, 2005.

MORAN, José Manuel. A educação que desejamos: novos desafios e como chegar lá. 2. ed. Campinas, SP: Papirus, 2007. 174 p.

. A integração das tecnologias na educação. Disponível em:

$\overline{<h t t p: / / w w w . e c a . u s p . b r / p r o f / m o r a n / i n t e g r a c a o . h t m>, ~ a c e s s o ~ e m ~} 14$ de maio de 2015.

PEIXOTO, J. CARVALHO, R. M. A. Mediação Pedagógica Midiatizada pelas tecnologias? Revista Teoria e Prática de Educação. v. 14 n. 1, 2011.

PRENSKY, Marc. Nativos digital, imigrantes digitais. MCB University Press, 2001.

ZEICHNER, K. M. A Formação Reflexiva de Professores: ideias e práticas. Trad. J. Carmona, M. J. Carvalho e M. Nóvoa. Lisboa: Educa, 1993.

RECEBIDO EM: 28/02/2016

APROVADO PARA PUBLICAÇÃO EM: 29/11/2016 